\title{
REGIONAL ECONOMIC STABILIZATION: AN EFFICIENT DIVERSIFICATION APPROACH
}

\author{
H. L. Brewer*
}

\begin{abstract}
This paper presents findings on three elements relevant to regional economic diversification and stability using concepts from portfolio theory. First, the empirical form of a frontier of efficient portfolios of manufacturing industries is computed and shown in risk/return space. This frontier represents the upper bounds for regional diversification aimed at maximizing expected values for given levels of risk. Second, diversification measures are computed for sample regions and are shown relative to the efficient frontier. Discussion reveals the portfolio approach prescribes superior normative guides relative to other approaches to diversification. Third, statistical tests are undertaken to determine if a portfolio diversification measure can explain cross-sectional differences in subsequently realized instability.
\end{abstract}

\section{Regional Economic Instability}

Interest in causes and cures of economic instability is generally heightened when extended periods of economic stagnation and decline are experienced, such as the recent situation in many countries. Along with interest in national economic trends, there is much attention from government officials, the popular press and academia regarding the cross-sectional experience of various subnational regions. With advances in communication and transportation it might be expected that greater economic integration would occur and that regional variation in the impact of national economic trends would diminish over time. However, Syron (1978) and Friedenberg (1980) report that regional experience seems to be becoming more dissimilar for the United States.

As a result of differing regional experience, a growing body of literature has addressed the issue of designing effective regional stabilization policies. Much of the discussion is related to the idea of economic diversification. Brown (1978) found that regions differ markedly in the mix of their industries. Industrial structure would not cause differences in regional experience if all industries had the same pattern of behavior over the business cycle. However, even casual observation suggests this is not the case. For instance, recent national recessionary periods have been attributed partly to rising energy prices while this same situation has benefited those regions with significant mining and petroleum industries. The combination of differences in industry mix and differing patterns of various industries renders some regions more susceptible to cyclical fluctuations than others. Based on ideas such as these, an industrial diversification theory of regional economic fluctuations has evolved. That is, variation in regional patterns of cyclical behavior can be attributed to differences in industrial mix.

Despite the intuitive appeal of this theory, empirical tests have been marred by inconsistency and controversy. After a review of early studies, many scholars suggested the industrial diversification theory left much to be desired. ${ }^{1}$ However, recent empirical studies by Conroy (1975) and Kort (1981) have provided new life to the theory. Both Conroy and Kort suggest that previous findings and inconsistencies were the result of data and measurement problems.

*Associate Professor, College of Business Administration, Oklahoma State University. Thanks to Richard Burgess for help with the quadratic programming software. The author gratefully acknowledges summer research support from the Dean's Excellence Fund and many suggestions for improvement from Ronald L. Moomaw. 
Conroy made a very important contribution by suggesting a portfolio theory approach to industrial diversification. He incorporated Siegel's (1966) measure of regional economic instability (REI) in crosssectional models where portfolio variance and other measures of industrial diversification were used as independent variables. Conroy found that portfolio variance was a statistically significant explanatory variable. He noted that the proportion of variation in REI explained by other diversification measures was less than one-eighth of that explained by the portfolio variance measure. Kort used a variance measure of REI similar to that of Conroy and alternative measures of industrial diversification in crosssectional regressions. His results indicated that, after using population size to correct for observed heteroscedasticity, an entropy measure of industrial diversification could explain $64.2 \%$ of the variation in REI across the sample regions. Subsequent investigation of Conroy's data reveals that, after correction for heteroscedasticity, the portfolio variance measure continues to best explain $88.3 \%$ of the crosssectional variation in REI. That a portfolio measure of diversification appears to outperform alternative measures in explaining observed behavior is not surprising when the theoretical constructs are considered. The other approaches focus on proximity to equal or national component weighting to measure diversification. The focus of the portfolio approach is on weights that lead to minimum variance in expected outcomes. Thus, when portfolio variance is chosen, the regression model uses statistical concepts of variation for both the dependent (REI) and independent (diversification) measures.

The work of Conroy and Kort indicates an ex post tie between observed REI and the industrial diversification of a region, with portfolio variance being the preferred measure of diversification. This study does not attempt to replicate the prior research which focused on historical REI and diversification explanatory variables. This paper uses the portfolio theory framework first introduced by Conroy, but presents three elements not found in his work. These new elements are found in parts III, IV, and V which follow a brief review of portfolio theory in part II. Part III develops a frontier, comprised of efficient portfolios of industries, which represents the upper bounds for regional diversification. This efficient frontier describes optimal tradeoffs between expected value and risk obtainable from the sample group of industries. Part IV presents portfolio diversification measures for a sample group of regional areas. An analysis of normative implications reveals that the portfolio approach prescribes diversification goals which are more meaningful than those prescribed by other approaches to diversification. Part V provides empirical results of tests to determine if the portfolio measure of diversification is related to subsequent economic instability. A summary and conclusions are contained in part VI.

\section{The Portfolio Approach to Diversification Specification and Measurement}

The portfolio approach to diversification was first developed in the field of financial economics and has received widespread acceptance there. Markowitz (1952) is generally credited with the first exposition of the concept of portfolio diversification. His work was directed toward the selection of securities to hold in an investment portfolio. Subsequently, the portfolio approach to diversification has been researched and applied extensively in the field of financial economics. ${ }^{2}$ In contrast, relatively little discussion of this approach is to be found in the literature of regional economics. Conroy (1974) demonstrated how alternative diversification strategies would affect a portfolio based measure of regional economic instability. Barth, et al., (1975), using employment data for Virginia, demonstrated how portfolio techniques could be used by policy makers in deciding which industries to attract to a region so as to reduce overall employment instability. St. Louis (1980) investigated the diversification of Canadian provinces using portfolio theory, ogive and national proportion measures.

Industrial diversification theory suggests that through diversification a region may be able to reduce its overall exposure to economic risk. Since proper diversification is the focus of modern portfolio theory, it is appropriate to investigate the value of a portfolio approach to help achieve economic stability. Portfolio theory focuses on efficient diversification. Efficient diversification is concerned not only with the diversification necessary to minimize exposure to risk, but also to maximize expected value.

The efficient approach to diversification is an ex ante model, built upon the random variable portfolio return, which focuses specifically on expected value (E) as a measure of return and the variance (V) of portfolio return, or its square root standard deviation $(\sigma)$, as a measure of riskiness. These characteristics are refined by the equations: 


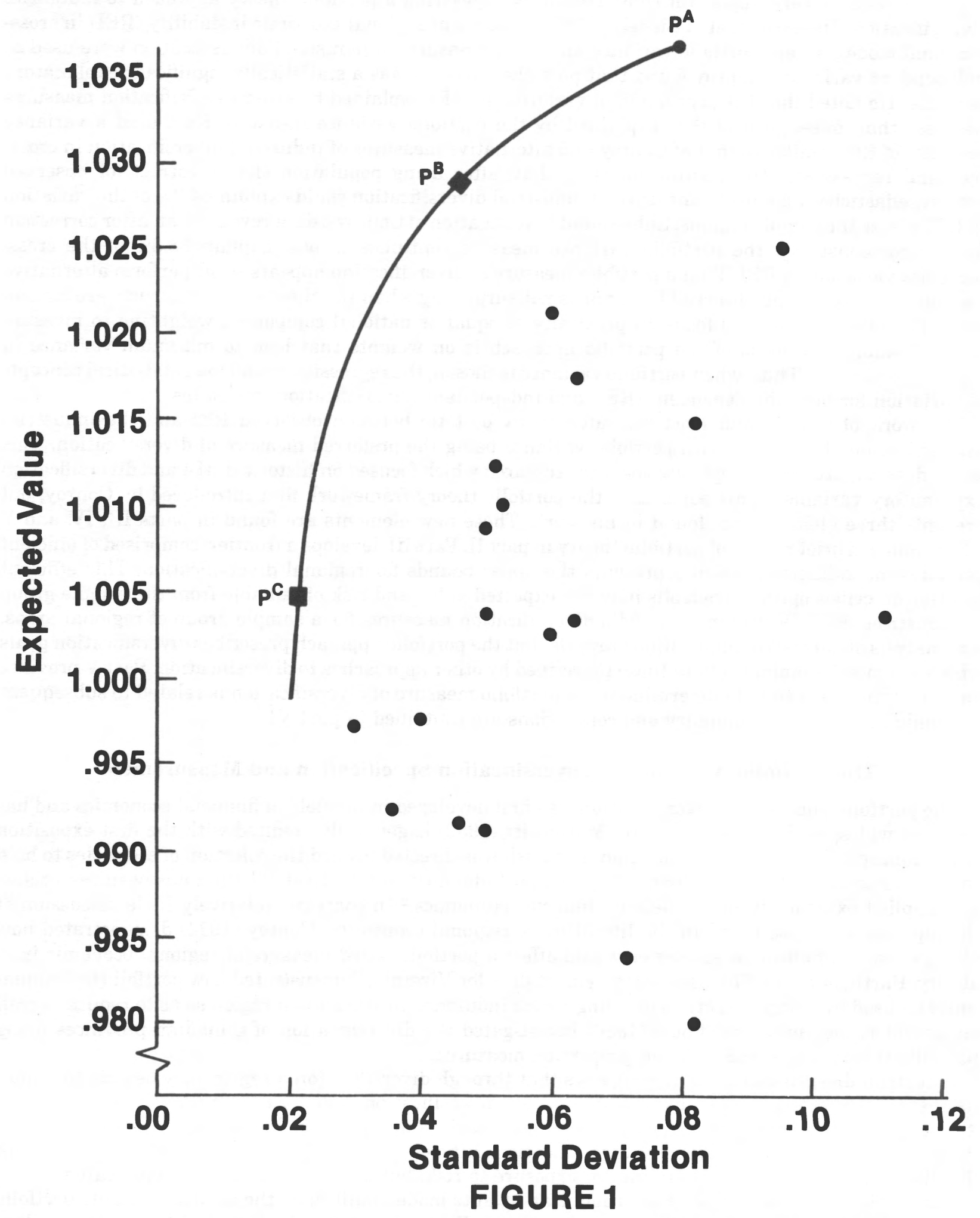

Efficient Frontier for Manufacturing Industries and Position of Individual Industries 


$$
\begin{gathered}
E=\sum_{j=1}^{n} W_{j} E_{j} \\
V=\sum_{i=1}^{n} \sum_{j=1}^{n} W_{i} W_{j} \rho_{i j} \sigma_{i} \sigma_{j}
\end{gathered}
$$

where $E_{j}$ is the expected value from component $j, W_{j}$ is the relative proportion of the entire portfolio which is represented by component $j, \rho_{\mathrm{ij}}$ is the correlation coefficient between the returns from components $i$ and $j, \sigma_{j}$ is the standard deviation of component $j$, and $n$ is the total number of components in the portfolio.

Markowitz formulated the problem of portfolio selection as one of minimizing $\mathrm{V}$ subject to given levels of $E$, where the $W_{j}$ are the relevant decision variables. Solution of this formulation provides an efficient frontier, such as shown by the curved line in Figure 1. The efficient frontier has the property of simultaneously minimizing risk for a given return and maximizing return for a given risk. All components and possible combinations of components are on or below this line.

\section{Determining Upper Bounds for Efficient Diversification}

To apply the portfolio approach to efficient diversification, we view a region as hosting a number of identifiable economic activities. Economic activities can be categorized in several ways. This study uses the Standard Industrial Classification (SIC) scheme. A measure of economic activity is also needed. Of the various measures possible, data availability suggests use of the number of persons employed in a particular SIC category. The procedure was to select a group of SIC categories to comprise a population of possible portfolio holdings for each region. Of the entire listing of SICs, it was decided to use the 20 categories within the manufacturing division. This selection was dictated by the availability of data concerning the composition of employment in a region as described later. The 20 manufacturing categories are shown in Table 1. The base measure for economic activity was 120 monthly employment figures at the national level for each of the 20 industries over the period 1972 through 1981 as reported in U.S. Department of Labor, Earnings and Employment (monthly). The average monthly employment during 1977 for each industry was determined and divided into each of the 120 monthly data points for that industry. This adjusts for the sizing differences among employment levels for each SIC code by producing employment relatives centered about 1977..$^{3}$ The mean and standard deviation of this employment relative for each industrial category, over the 1972-1981 period, are shown in Table 1 . These mean and standard deviation coordinates are also indicated below the curve on Figure 1.

Next, the possible efficient combinations of economic activities, represented by 20 manufacturing categories, was obtained by computing efficient sets of portfolios. The portfolio selection algorithm used was that demonstrated by Markowitz (1959). The analysis used monthly data for 1972-1981 and the resulting efficient frontier, as plotted by the solid curve in the risk-return space of Figure 1, represents expectations for the next period. These expectations are thus based on the employment performance of each industry over the past 10 years. ${ }^{4}$

Of the numerous corner portfolios along the efficient frontier in Figure 1, only a limited number are identified here for illustrative purposes. Portfolio PA contains only SIC 36, Electrical and Electronic machinery. As noted in Table 1, SIC 36 has the highest mean employment relative. Portfolio $\mathrm{P}^{\mathrm{B}}$ calls for $62 \%$ of SIC 36 and $38 \%$ of SIC 31 . Portfolio PC is represented by five industries as follows: $43 \%$, SIC 28 ; $32 \%$, SIC $31 ; 20 \%$, SIC $27 ; 4 \%$, SIC $20 ; 1 \%$, SIC 29 . The efficient portfolio at $P^{C}$ has an expected employment relative E of 1.005 using Equation (1) and a standard deviation of .021 using Equation (2). It is efficient only if one is willing to base future expectations for various industries on how they have performed in the past.

A central ingredient of the portfolio approach is the determination of combinations which reduce overall portfolio risk. In the current case, this means that an industry will be an attractive candidate for an efficient portfolio if it has a relatively low correlation with other industries. To demonstrate this feature, the correlation matrix for the five industries represented in portfolio $\mathrm{PC}^{\mathrm{C}}$ is presented in Table 2. The presence of low correlations should serve to indicate that employment variation across industries is not necessarily highly correlated. There are substantial opportunities for diversification among various industrial categories. 


\section{TABLE 1}

Characteristics of Manufacturing Categories Used in Portfolio Analysis

\begin{tabular}{|c|c|c|c|}
\hline SIC & Description & $\begin{array}{c}\text { Mean } \\
\text { Employment } \\
\text { Relative }\end{array}$ & $\begin{array}{l}\text { Standard } \\
\text { Deviation }\end{array}$ \\
\hline 20 & Food and Kindred Products & .988 & .040 \\
\hline 21 & Tobacco Manufactures & .713 & .290 \\
\hline 22 & Textile Mill Products & 1.004 & .063 \\
\hline 23 & Apparel and Fabric Goods & 1.004 & .049 \\
\hline 24 & Lumber and Wood Products & .984 & .072 \\
\hline 25 & Furniture and Fixtures & 1.002 & .061 \\
\hline 26 & Paper and Allied Products & .998 & .029 \\
\hline 27 & Printing and Publishing & 1.018 & .064 \\
\hline 28 & Chemicals and Allied Products & .993 & .035 \\
\hline 29 & Petroleum Refining and Related & .991 & .051 \\
\hline 30 & Rubber and Plastic Products & .980 & .081 \\
\hline 31 & Leather and Leather Goods & 1.015 & .081 \\
\hline 32 & Stone, Clay, Glass \& Concrete & 1.012 & .051 \\
\hline 33 & Primary Metal Industries & 1.010 & .052 \\
\hline 34 & Fabricated Metal Products & 1.009 & .051 \\
\hline 35 & Machinery, Except Electrical & 1.026 & .096 \\
\hline 36 & Electrical \& Electronic & 1.036 & .079 \\
\hline 37 & Transportation Equipment & 1.003 & .059 \\
\hline 38 & Measuring \& Controlling & 1.004 & .112 \\
\hline 39 & Miscellaneous Manufacturing & .991 & .046 \\
\hline
\end{tabular}

Source: Calculated from Department of Labor employment time series.

The next procedure was to select a sample of regions to be investigated. For this study, the regions consisted of Standard Metropolitan Statistical Areas (SMSAs). Using the criteria of a labor force of between 200,000 and 600,00 persons during January of 1982, a group of 56 SMSAs was identified. The labor force measurement was taken from U.S. Department of Labor, Earnings and Employment (April, 1982). The sample of 56 SMSAs is identified in Table 3.

To determine the existing composition of manufacturing industries within each SMSA, the U.S. Department of Commerce, 1977 Census of Manufactures was used. This survey is conducted every five

TABLE 2

Correlation Coefficient Matrix for Selected* Industries

\begin{tabular}{llrrrrr}
\hline SIC & Description & 20 & 27 & 28 & 29 & 31 \\
\hline 20 & Food \& Kindred & 1.00 & & & & \\
27 & Printing \& Publishing & .08 & 1.00 & & & \\
28 & Chemicals \& Allied & .20 & .89 & 1.00 & & \\
29 & Petroleum Refining & .42 & .46 & .52 & 1.00 & \\
31 & Leather \& Leather Goods & .16 & .71 & .67 & .32 & 1.00 \\
\hline
\end{tabular}

*Manufacturing categories included in the efficient portfolio at Pc on Figure 2. 
Regional Economic Stabilization

TABLE 3

Characteristics of SMSAs Examined

\begin{tabular}{|c|c|c|c|c|}
\hline & SMSA & $\begin{array}{c}\text { Labor }^{1} \\
\text { Force } \\
(000 s)\end{array}$ & $\begin{array}{c}\text { Expected }^{2} \\
\text { Value }\end{array}$ & $\begin{array}{l}\text { Standard }^{3} \\
\text { Deviation }\end{array}$ \\
\hline 1 & Akron, OH & 298.4 & 1.000 & .062 \\
\hline 2 & Albany, NY & 380.4 & 1.007 & .036 \\
\hline 3 & Albuquerque, NM & 209.0 & 1.011 & .047 \\
\hline 4 & Allentown, PA & 309.1 & 1.009 & .035 \\
\hline 5 & Austin, TX & 285.9 & 1.017 & .053 \\
\hline 6 & Baton Rouge, LA & 224.8 & .996 & .033 \\
\hline 7 & Birmingham, $\mathrm{AL}$ & 375.9 & 1.008 & .041 \\
\hline 8 & Buffalo, NY & 570.2 & 1.010 & .048 \\
\hline 9 & Charlotte, NC & 370.9 & 1.004 & .032 \\
\hline 10 & Chattanooga, TN & 206.0 & 1.007 & .033 \\
\hline 11 & Columbus, $\mathrm{OH}$ & 554.8 & 1.012 & .052 \\
\hline 12 & Dayton, $\mathrm{OH}$ & 389.5 & 1.012 & .061 \\
\hline 13 & Flint, MI & 228.9 & 1.008 & .046 \\
\hline 14 & Fort Lauderdale, FL & 477.7 & 1.017 & .061 \\
\hline 15 & Fresno, CA & 279.7 & 1.005 & .040 \\
\hline 16 & Gary, IN & 291.3 & 1.009 & .046 \\
\hline 17 & Grand Rapids, MI & 323.2 & 1.012 & .050 \\
\hline 18 & Greensboro, NC & 445.1 & 1.008 & .034 \\
\hline 19 & Greenville, SC & 284.5 & 1.007 & .035 \\
\hline 20 & Harrisburg, PA & 235.4 & 1.011 & .035 \\
\hline 21 & Hartford, CT & 389.8 & 1.017 & .062 \\
\hline 22 & Honolulu, HI & 343.1 & 1.001 & .032 \\
\hline 23 & Jacksonville, FL & 337.9 & 1.004 & .037 \\
\hline 24 & Jersey City, NJ & 245.2 & 1.008 & .034 \\
\hline 25 & Knoxville, TN & 228.4 & 1.005 & .035 \\
\hline 26 & Lansing, MI & 245.5 & 1.016 & .059 \\
\hline 27 & Las Vegas, NV & 266.3 & .992 & .035 \\
\hline 28 & Long Branch, NJ & 238.3 & 1.010 & .049 \\
\hline 29 & Memphis, TN & 407.2 & 1.004 & .041 \\
\hline 30 & Nashville, TN & 427.2 & 1.009 & .040 \\
\hline 31 & New Brunswick, NJ & 328.4 & 1.003 & .044 \\
\hline 32 & New Orleans, LA & 509.4 & 1.005 & .039 \\
\hline 33 & Norfolk, VA & 337.8 & 1.002 & .039 \\
\hline 34 & Northeast, PA & 285.5 & 1.008 & .037 \\
\hline 35 & Oklahoma City, OK & 454.6 & 1.007 & .050 \\
\hline 36 & Omaha, NE & 280.1 & 1.011 & .044 \\
\hline 37 & Orlando, FL & 365.1 & 1.014 & .046 \\
\hline 38 & Oxnard, CA & 256.8 & 1.013 & .053 \\
\hline 39 & Paterson, NJ & 206.9 & 1.009 & .041 \\
\hline 40 & Providence, RI & 469.0 & 1.004 & .040 \\
\hline 41 & Raleigh, NC & 308.2 & 1.017 & .049 \\
\hline 42 & Richmond, VA & 336.7 & 1.002 & .036 \\
\hline
\end{tabular}

1Labor force for January, 1982. U.S. Department of Labor, Earnings and Employment (April 1982).

${ }^{2}$ Calculated using Equation (1).

sCalculated using Equation (2). 
TABLE 3 (continued)

Characteristics of SMSAs Examined

\begin{tabular}{|c|c|c|c|c|}
\hline & SMSA & $\begin{array}{c}\text { Labor }^{1} \\
\text { Force } \\
(000 \mathrm{~s})\end{array}$ & $\begin{array}{l}\text { Expected }^{2} \\
\text { Value }\end{array}$ & $\begin{array}{l}\text { Standard }^{3} \\
\text { Deviation }\end{array}$ \\
\hline 43 & Rochester, NY & 483.9 & 1.010 & .082 \\
\hline 44 & Sacramento, CA & 507.0 & 1.000 & .041 \\
\hline 45 & Salt Lake City, UT & 434.8 & 1.013 & .052 \\
\hline 46 & San Antonio, TX & 461.9 & 1.008 & .035 \\
\hline 47 & Springfield, MA & 279.2 & 1.006 & .044 \\
\hline 48 & Syracuse, NY & 301.2 & 1.013 & .051 \\
\hline 49 & Toledo, $\mathrm{OH}$ & 355.7 & 1.008 & .047 \\
\hline 50 & Tucson, AZ & 233.4 & 1.017 & .048 \\
\hline 51 & Tulsa, OK & 360.5 & 1.014 & .054 \\
\hline 52 & West Palm Beach, FL & 280.2 & 1.013 & .041 \\
\hline 53 & Wichita, KS & 224.0 & 1.012 & .059 \\
\hline 54 & Wilmington, DE & 253.9 & 1.000 & .037 \\
\hline 55 & Worcester, MA & 200.5 & 1.007 & .036 \\
\hline 56 & Youngstown, $\mathrm{OH}$ & 232.8 & 1.010 & .044 \\
\hline \multicolumn{2}{|c|}{ Mean } & 332.4 & 1.008 & .045 \\
\hline \multicolumn{2}{|c|}{ Standard Deviation } & 96.9 & .005 & .009 \\
\hline
\end{tabular}

${ }^{1}$ Labor force for January, 1982. U.S. Department of Labor, Earnings and Employment (April 1982).

${ }^{2}$ Calculated using Equation (1).

${ }^{3}$ Calculated using Equation (2).

years, and 1977 was a convenient midpoint for the time period of this study. To measure the diversification of a given SMSA, the procedure was to compute expected value and risk characteristics for its economic activity using Equations (1) and (2), and locate the SMSA in risk return space on Figure 2. These measures are a combination of the expected values and covariances for the industries at the national level, and weightings by industry from the individual SMSAs. ${ }^{5}$

\section{Portfolio Diversification and Normative Implications}

Table 3 and Figure 2 present results of the portfolio analysis of SMSA diversification. Findings relate to the expected diversification of the SMSAs as of the end of 1981, where expectations are based on extrapolations of the past ten years of monthly employment performance for each of the industrial categories. Furthermore, results are based on the homogeneity assumption which does not allow for firm uniqueness within SMSAs. Although diversification is discussed here, recall that previous researchers have found that the extent of industrial diversification has significance when used to explain observed economic instability.

Figure 2 indicates a broad spread of SMSAs with respect to expected diversification. The efficient frontier shown here was taken from the potential efficient frontier of Figure 1. While none could be considered close to the efficient frontier, some SMSAs appear to have a more desirable combination of industries so as to take advantage of low correlations. It has already been demonstrated, by observing the holdings of $\mathrm{P}^{\mathrm{C}}$ (five categories), that a high number of categories is not prerequisite to efficient diversification.

It can be argued that while an SMSA might be successful in attracting a certain mix of industries, it would almost certainly be unsuccessful in attaining particular employment proportions across industries. 


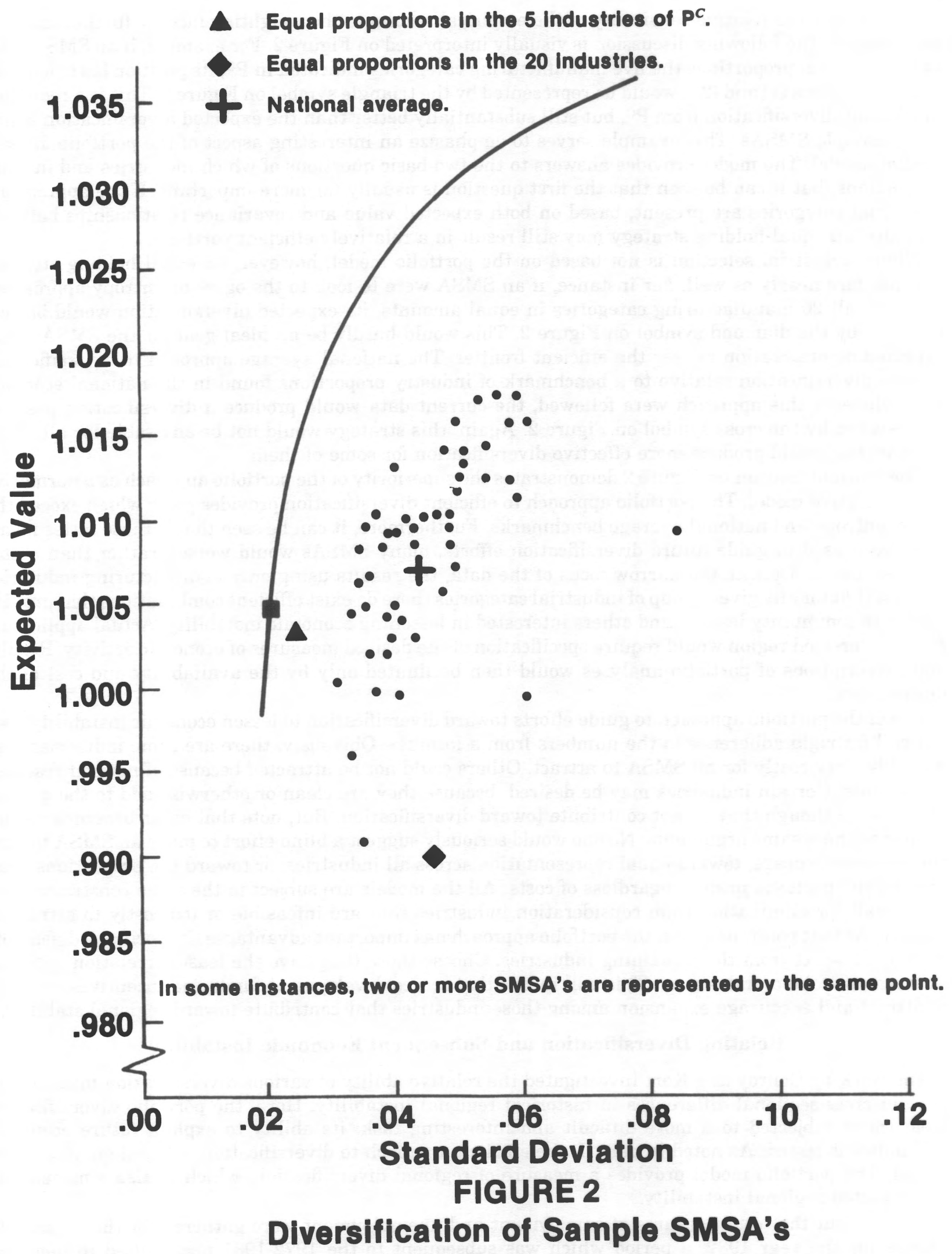


To investigate the relative sensitivity of the empirical results to the weighting factors, further analysis is necessary. The following discussion is visually interpreted on Figure 2. For example, if an SMSA were to host in equal proportions the five manufacturing categories indicated in $\mathrm{PC}$, its position [as calculated using Equations (1) and (2)], would be represented by the triangle symbol on Figure 2. This is a reduction in efficient diversification from $\mathrm{PC}$, but still substantially better than the expected diversification of any of the sample SMSAs. This example serves to emphasize an interesting aspect of the portfolio diversification model. The model provides answers to the two basic questions of which industries and in what proportions, but it can be seen that the first question is usually far more important. If the appropriate industrial categories are present, based on both expected value and covariance relationships between all pairs, an equal holding strategy may still result in a relatively efficient portfolio.

Where industrial selection is not based on the portfolio model, however, an equal holding strategy will not fare nearly as well. For instance, if an SMSA were to look to the ogive or entropy approaches and host all 20 manufacturing categories in equal amounts, its expected diversification would be represented by the diamond symbol on Figure 2. This would hardly be an ideal goal for the SMSAs with expected diversification nearer the efficient frontier. The national average approach to diversification defines diversification relative to a benchmark of industry proportions found in the national economy as a whole. If this approach were followed, the current data would produce a diversification position represented by the cross symbol on Figure 2. Again, this strategy would not be advisable for all of the SMSAs, but would produce more effective diversification for some of them.

The efficient frontier on Figure 2 demonstrates the superiority of the portfolio approach as a normative or prescriptive model. The portfolio approach to efficient diversification provides goals which exceed the ogive, entropy and national average benchmarks. Furthermore, it can be seen that if these latter measures were used to guide future diversification efforts, many SMSAs would worsen rather than better their situation. Despite the narrow focus of the data, the results using only manufacturing industries suggest that for any given group of industrial categories there do exist efficient combinations that provide guides to community leaders and others interested in lessening economic instability. Actual application for an interested region would require specification of the desired measures of economic activity. Results and prescriptions of portfolio analyses would then be limited only by the availability and cost of the desired data.

Use of the portfolio approach to guide efforts toward diversification to lessen economic instability does not call for rigid adherence to the numbers from a formula. Obivously, there are some industries that would be very costly for an SMSA to attract. Others could not be attracted because of natural resource constraints. Certain industries may be desired, because they are clean or otherwise add to the quality of life, even though they do not contribute toward diversification. But, note that other benchmarks are subject to these same arguments. No one would seriously suggest a blind effort to move an SMSA toward the national average, toward equal representation across all industries, or toward the proportions specified by the portfolio model, regardless of costs. All the models are subject to the same constraints and would call for elimination from consideration industries that are infeasible or too costly to attract or remove. At that point, however, the portfolio approach has important advantages. It specifies a defensible method to select from the remaining industries. Choose those that have the least correlation with the existing portfolio of industries. This will insure that scarce development funds and incentives are used to attract and encourage expansion among those industries that contribute toward regional stability.

\section{Relating Diversification and Subsequent Economic Instability}

The work by Conroy and Kort investigated the relative ability of various diversification measures to explain cross-sectional differences in historical regional instability. Here, the portfolio diversification measure is subjected to a more difficult and interesting task; its ability to explain future economic instability is tested. As noted in part II, the efficient approach to diversification is based on an ex ante model. The portfolio model provides a measure of regional diversification, which is also a measure of the expected regional instability.

To carry out the test, measures of employment and unemployment were gathered for the 56 sample SMSAs for the year 1982, a period which was subsequent to the 1972-1981 period used to measure diversification. Table 4 lists the percent change in manufacturing employment (PCME) and the percent 
change in unemployment (PCNU) experienced in each of the SMSAs during 1982. PCME and PCNU serve as measures of experienced returns (employment) and risks (unemployment) for the sample SMSAs during 1982. Together they provide a picture of the stability of each region by capturing the in and out migration of the labor force as well as the changing experience of the more permanent labor force.

The coefficient of variation of the portfolio of industrial holdings (PORTVAR) used to measure the diversification and expected instability for each of the SMSAs is given in Table $4 .{ }^{6}$ It is derived from the expected value and standard deviation measures given in Table 3. PORTVAR is a relative measure of risk for given returns. Larger values of PORTVAR are associated with decreased diversification and increased expected instability. Larger positive values of PCNU indicate increased observed instability. The relationship between PORTVAR and PCNU is expected to be positive. Figure 2 indicates a positive relationship between risk and expected value. Thus, the relationship between PORTVAR and PCME is expected to be positive. PORTVAR provides a measure of return adjusted risk. Similarly, the ratio of PCME to PCNU provides a measure of risk adjusted return.

The hypothesis is that there exists a positive relationship between diversification as measured by PORTVAR and subsequent stability as measured by PCME/PCNU. Related research by the author indicates a relationship between logarithmic measures of SMSA size, instability and diversification. Therefore the hypothesis is tested using the regression equation given by:

\section{(3) PCME $_{i} /$ PCNU $_{i}=a+$ b PORTVAR $i+c$ LMFG81 $_{i}+E_{i}$}

where LMFG81 i is the logarithm of average manufacturing employment during 1981 for each SMSA, $\mathrm{E}$ is the disturbance term and the other terms are as specified above. The significance of a positive coefficient for PORTVAR is tested against the null hypothesis of a zero coefficient. Results of the regression are given in Table 5. Several conclusions are evident from the table. The diversification coefficient, PORTVAR, has a positive sign. This indicates the relationship between a portfolio measure of diversification and subsequently experienced instability is in the direction predicted. The $t$ statistic indicates that the positive relationship between instability and PORTVAR is significant at the .05 level. The log of manufacturing employment is also significantly related to SMSA stability. Analysis of the regression results indicates that, holding employment constant, a portfolio diversification measure has statistical significance in explaining cross sectional differences in subsequently realized instability.

\section{Summary and Conclusions}

This paper presents analysis of SMSA diversification and instability. It uses employment measures of SMSA economic activity. The empirical analysis of upper bounds for efficient diversification and SMSA diversification was based on national employment experience for a population of 20 manufacturing industries together with the industry proportions existing in each of 56 SMSAs. The findings demonstrate there are combinations of industries that provide expected return and risk superior to other combinations. Holdings across a large number of industries are not necessary to achieve optimal combinations. Further analysis suggested that certain SMSAs are better situated than others to benefit from efficient employment diversification. While this may have occurred from design or chance, it sets a standard of improvement open to less diversified SMSAs. It was shown that the concept of efficient diversification provides a normative goal which should be preferred to more common definitions of diversification which envision equal or average industrial proportions. Efficient diversification identifies combinations which, without the need for a large number of components, minimize risk for given levels of expected values. Unlike other measures of diversification, diversification in the efficient sense incorporates statistical variance and thus has a logical relationship with variance measures of regional economic stability.

Previous research has indicated a tie between measures of SMSA diversification and historical instability. Tests conducted here focus on diversification and future instability. Results indicate a portfolio measure of diversification is significantly related to subsequently realized instability for the sample SMSAs.

It is useful to compare industrial diversification against other tools to achieve regional economic stability. Countercyclical government spending is often suggested to combat economic decline. However, Allen (1982) suggests that federal outlays focused on a specific region often do not have the desired 
TABLE 4

Diversification, Size and Stability Measures

\begin{tabular}{|c|c|c|c|c|c|c|}
\hline & SMSA & PORTVAR ${ }^{1}$ & $\begin{array}{c}\text { MFG812 }^{2} \\
(000 \mathrm{~s})\end{array}$ & $\mathrm{PCME}^{3}$ & $\mathrm{PCNU}^{4}$ & $\begin{array}{l}\text { PCME/ } \\
\text { PCNU }\end{array}$ \\
\hline 1 & Akron, OH & 6.178 & 75.7 & -.091 & .251 & -.363 \\
\hline 2 & Albany, NY & 3.559 & 56.6 & -.078 & .124 & -.625 \\
\hline 3 & Albuquerque, NM & 4.646 & 17.8 & .006 & .106 & .053 \\
\hline 4 & Allentown, PA & 3.517 & 103.9 & -.095 & .285 & -.334 \\
\hline 5 & Austin, TX & 5.179 & 33.4 & -.006 & .122 & -.049 \\
\hline 6 & Baton Rouge, LA & 3.341 & 26.7 & -.037 & .120 & -.313 \\
\hline 7 & Birmingham, AL & 4.063 & 60.4 & -.121 & .326 & -.371 \\
\hline 8 & Buffalo, NY & 4.724 & 129.5 & -.126 & .303 & -.416 \\
\hline 9 & Charlotte, NC & 3.235 & 94.5 & -.043 & .426 & -.102 \\
\hline 10 & Chattanooga, TN & 3.298 & 48.4 & -.089 & .122 & -.728 \\
\hline 11 & Columbus, $\mathrm{OH}$ & 5.107 & 93.1 & -.069 & .173 & -.397 \\
\hline 12 & Dayton, OH & 5.990 & 97.8 & -.101 & .348 & -.291 \\
\hline 13 & Flint, MI & 4.515 & 72.6 & -.147 & .371 & -.398 \\
\hline 14 & Fort Lauderdale, FL & 6.005 & 42.7 & -.056 & .454 & -.124 \\
\hline 15 & Fresno, CA & 3.980 & 22.9 & -.066 & .363 & -.181 \\
\hline 16 & Gary, IN & 4.605 & 90.7 & -.149 & .323 & -.461 \\
\hline 17 & Grand Rapids, MI & 4.943 & 90.1 & -.057 & .323 & -.175 \\
\hline 18 & Greensboro, NC & 3.396 & 150.0 & -.048 & .435 & -.110 \\
\hline 19 & Greenville, SC & 3.496 & 103.1 & -.053 & .460 & -.116 \\
\hline 20 & Harrisburg, PA & 3.420 & 42.1 & -.052 & .111 & -.470 \\
\hline 21 & Hartford, CT & 6.091 & 97.8 & -.070 & .138 & -.505 \\
\hline 22 & Honolulu, HI & 3.181 & 16.8 & -.024 & .257 & -.093 \\
\hline 23 & Jacksonville, FL & 3.649 & 34.2 & -.029 & .230 & -.127 \\
\hline 24 & Jersey City, NJ & 3.411 & 66.1 & -.089 & .230 & -.388 \\
\hline 25 & Knoxville, TN & 3.511 & 51.5 & -.037 & .191 & -.193 \\
\hline 26 & Lansing, MI & 5.787 & 40.9 & -.090 & .165 & -.547 \\
\hline 27 & Las Vegas, NV & 3.576 & 7.3 & -.096 & .439 & -.218 \\
\hline 28 & Long Branch, NJ & 4.810 & 25.3 & -.047 & .280 & -.170 \\
\hline 29 & Memphis, TN & 4.064 & 59.5 & -.086 & .170 & -.505 \\
\hline 30 & Nashville, TN & 3.957 & 84.1 & -.077 & .281 & -.276 \\
\hline 31 & New Brunswick, NJ & 4.379 & 89.4 & -.074 & .315 & -.234 \\
\hline 32 & New Orleans, LA & 3.873 & 52.2 & -.088 & .189 & -.466 \\
\hline 33 & Norfolk, VA & 3.871 & 29.3 & -.061 & .166 & -.370 \\
\hline 34 & Northeast, PA & 3.694 & 68.7 & -.066 & .093 & -.704 \\
\hline 35 & Oklahoma City, OK & 4.958 & 55.8 & -.072 & .515 & -.139 \\
\hline 36 & Omaha, NE & 4.305 & 34.2 & -.058 & .396 & -.148 \\
\hline 37 & Orlando, FL & 4.578 & 39.7 & -.005 & .159 & -.032 \\
\hline 38 & Oxnard, CA & 5.186 & 25.0 & .044 & .545 & .081 \\
\hline 39 & Paterson, NJ & 4.043 & 66.5 & -.057 & .259 & -.220 \\
\hline 40 & Providence, RI & 3.949 & 141.0 & -.082 & .387 & -.212 \\
\hline 41 & Raleigh, NC & 4.781 & 45.8 & -.002 & .164 & -.013 \\
\hline
\end{tabular}

${ }^{1}$ Coefficient of variation. (standard deviation $\div$ expected value times 100 )

2Average manufacturing employment during 1981. U.S. Department of Labor, Earnings and Employment (May 1983).

3Percent change in average manufacturing employment from 1981 to 1982 . Earnings and Employment (May 1983).

4Percent change in average number unemployed from 1981 to 1982. Earnings and Employment (May 1983). 
TABLE 4 (continued)

Diversification, Size and Stability Measures

\begin{tabular}{|c|c|c|c|c|c|c|}
\hline & SMSA & PORTVAR $^{1}$ & $\begin{array}{c}\text { MFG812 }^{2} \\
(000 \mathrm{~s})\end{array}$ & $\mathrm{PCME}^{3}$ & $\mathrm{PCNU}^{4}$ & $\begin{array}{l}\text { PCME/ } \\
\text { PCNU }\end{array}$ \\
\hline 42 & Richmond, VA & 3.634 & 56.6 & -.023 & .360 & -.064 \\
\hline 43 & Rochester, NY & 8.157 & 159.0 & -.009 & .242 & -.039 \\
\hline 44 & Sacramento, CA & 4.128 & 27.5 & -.036 & .341 & -.107 \\
\hline 45 & Salt Lake City, UT & 5.105 & 61.5 & -.028 & .168 & -.164 \\
\hline 46 & San Antonio, TX & 3.521 & 52.5 & -.036 & .142 & -.255 \\
\hline 47 & Springfield, MA & 4.405 & 63.2 & -.082 & .223 & -.368 \\
\hline 48 & Syracuse, NY & 5.047 & 59.5 & -.062 & .159 & -.390 \\
\hline 49 & Toledo, $\mathrm{OH}$ & 4.691 & 74.6 & -.078 & .170 & -.457 \\
\hline 50 & Tucson, AZ & 4.758 & 24.3 & .033 & .843 & .039 \\
\hline 51 & Tulsa, OK & 5.376 & 68.3 & -.081 & .792 & -.102 \\
\hline 52 & West Palm Beach, FL & 4.048 & 29.1 & -.024 & .384 & -.063 \\
\hline 53 & Wichita, KS & 5.813 & 64.3 & -.184 & 1.032 & -.178 \\
\hline 54 & Wilmington, DE & 3.740 & 65.0 & -.057 & .166 & -.343 \\
\hline 55 & Worcester, MA & 3.597 & 47.8 & -.082 & .517 & -.158 \\
\hline 56 & Youngstown, $\mathrm{OH}$ & 4.388 & 67.3 & -.207 & .638 & -.324 \\
\hline \multirow{2}{*}{\multicolumn{2}{|c|}{$\begin{array}{l}\text { Mean } \\
\text { Standard Deviation }\end{array}$}} & 4.415 & 62.6 & -.064 & .308 & 0.258 \\
\hline & & .965 & 33.5 & .046 & .191 & .188 \\
\hline
\end{tabular}

${ }^{1}$ Coefficient of variation. (standard deviation $\div$ expected value times 100 )

${ }^{2}$ Average manufacturing employment during 1981. U.S. Department of Labor, Earnings and Employment (May 1983).

3Percent change in average manufacturing employment from 1981 to 1982 . Earnings and Employment (May 1983).

4 Percent change in average number unemployed from 1981 to 1982. Earnings and Employment (May 1983).

multiplier effect because of sizeable leakages to other regions. Local countercyclical measures are hampered by limited tax bases and debt limits. In contrast to government spending prescriptions, industrial diversification focuses on working within the framework of private enterprise to mitigate economic instability. The role of government and other community leaders would be to identify and encourage those industries that will contribute toward efficient portfolios of industries. With regard to the encouragement process, two recent articles are of interest. Erickson (1976) reports that only one newly

\section{TABLE 5}

Regression of Instability on PORTVAR and Size

Results from Equation (3)

\begin{tabular}{lcc}
\multicolumn{1}{c}{ Term } & Coefficient & 't' Statistic \\
\hline PORTVAR & .0452 & $1.77^{*}$ \\
LMFG81 & -.1050 & $2.54^{* *}$ \\
Constant & -.0389 & 0.22 \\
\hline
\end{tabular}

*Significant at .05 level (one-tail test)

**Significant at .01 level (one-tail test)

Standard Error of Estimate (.1782)

Adjusted R-square (.13) 
located firm out of 108 respondents cited industrial revenue bond financing as an attribute in the location decision. None mentioned tax holidays or incentives. In a study of determinants of new capital formation, Browne, et al. (1980) suggest that wage rates have declined in importance, while frequency of labor disputes and right to work laws have increased in importance.

While not a panacea, a portfolio measure of diversification, which includes both expected values and a measure of risk, should prove useful as an additional tool for those concerned about regional economic instability. The portfolio approach to efficient diversification is not intended to replace the decisionmaking process, but rather to assist in evaluating alternatives.

\section{FOOTNOTES}

${ }^{1}$ See Conroy (1974 and 1975) for a summary of these early studies and the comments of leading scholars.

${ }^{2}$ Such work includes studies of common stocks [Sharpe (1966) and Jensen (1968)], bonds [Cheng (1962)], forest land [Mills and Hoover (1982)], real estate [Friedman (1971)], mixed assets [Robichek et al. (1972)], conglomerates [Smith and Schreiner (1969)], capital budgeting [Weingartner (1966)], insurance firms [Blasch et al. (1977)], bank holding companies [Eisemann (1976)], and international investment diversification [Errunza and Senbet (1981)].

3Various arguments and treatments have been used to adjust or not adjust these time series for seasonal, trend and other components. See Conroy (1975, p. 497), Barth et al. (1975, p. 11) and St. Louis (1980, p. 24).

${ }^{4}$ Support for the use of ex post data to form ex ante expectations is found in Markowitz (1959) and Cohen and Pogue (1967).

5This method of combination was used by Smith and Schreiner (1969) and by Conroy (1975). There are certain shortcomings to be noted. Each SMSA is host to a number of specifically identifiable firms or organizations. Each of these organizations can be matched to an SIC code. However, the Department of Labor's employment measures by SIC code may not closely mirror the experience of a particular firm in a given region. But, the lack of employment data for individual organizations within each SMSA forces the use of aggregate data. Thus, if a SMSA hosted an electronics firm, this study assumes measures from the electronics industry. The probable effect of any measurement error is to bias toward zero the estimate of the coefficient of PORTVAR reported in Part V.

${ }^{6}$ Measures similar in spirit were used by Smith and Schreiner (1969) and by Conroy (1975). Although both the measure used here and Conroy's measure are coefficients of variation, the label portfolio variance (PORTVAR) is used for consistency and comparison with Conroy. St. Louis (1980) noted the problems in trying to rank SMSAs relative to a frontier when both a curved frontier and a region's utility function must be considered. His measure attempts to account for the curved frontier, but not for preference functions. The considerations noted by St. Louis do not hinder this research for two reasons. First, inspection of Figure 2 indicates that, for this set of data, the curved frontier poses little, if any, problem for a linear measure such as the coefficient of variation. Second, the study measures the relationship between observed instability and an independent variable given by the ratio of standard deviation to expected value.

\section{REFERENCES}

Allen, Larry, 1982. Regional Economic Stabilization and the Acceleration Principle. Growth and Change 13:2 (April): 10-17.

Barth, James, John Kraft and Philip Wiest, 1975. A Portfolio Theoretic Approach to Industrial Diversification and Regional Employment. Journal of Regional Science 15:1 (April): 9-15.

Blasch, Howard F., J.D. Hammond and Ned Shilling, 1977. Planning Insurance Company Line Mix for Profit Maximization. Risk Management 24:9 (September): 41-50.

Browne, Lynn E., 1978. Regional Industry Mix and the Business Cycle. New England Economic Review (November/December): 35-53.

Browne, Lynn E., Peter Mieszkowski and Richard R. Syron, 1980. Regional Investment Patterns. New England Economic Review (July/August): 5-23.

Cheng, Pao Lua, 1968. Optimal Bond Portfolio Selection. Management Science 14:8 (July): 490-499.

Cohen, Kalman J. and Jerry A. Pogue, 1967. An Empirical Evaluation of Alternative Portfolio-Selection Models. Journal of Business 40:2 (April): 166-193.

Conroy, Michael E, 1974. Alternative Strategies for Regional Industrial Diversification. Journal of Regional Science 14:1 (April): 31-46.

Conroy, Michael E., 1975. The Concept and Measurement of Regional Industrial Diversification. Southern Economic Journal 41:3 (January): 492-505.

Eiseman, Peter C., 1976. Diversification and the Congeneric Bank Holding Company. Journal of Bank Research 7:1 (Spring): 6877.

Erickson, Rodney A., 1976. Nonmetropolitan Industrial Expansion: Emerging Implications for Regional Development. Review of Regional Studies 6:1 (Spring): 35-48.

Errunza, Vihang R. and Lemma W. Senbet, 1981. The Effects of International Operations on the Market Value of the Firm: Theory and Evidence. Journal of Finance 36:2 (May): 401-418.

Friedenberg, Howard and Robert Bretzfelder, 1980. Sensitivity of Regional and State Nonfarm Wages and Salaries to National Business Cycles: 1948-1979. Survey of Current Business 60:5 (May): 15-27.

Friedman, Harris C., 1971. Mixed Asset Portfolios and Real Estate Investment. Federal Home Loan Bank Board Journal 4:3 (March): 9-27.

Jensen, Michael C., 1968. The Performance of Mutual Funds in the Period 1945-1964. Journal of Finance 23:2 (May): 389-416. 
Kort, John R., 1981. Regional Economic Instability and Industrial Diversification in the U.S. Land Economics 57:4 (November): 596-608.

Markowitz, Harry M., 1952. Portfolio Selection. Journal of Finance 7:1 (March): 77-91.

Markowitz, Harry M., 1959. Portfolio Selection: Efficient Diversification of Investments. New York: John Wiley \& Sons.

Mills, W.L. Jr. and William L. Hoover, 1982. Investment in Forest Land: Aspects of Risk and Diversification. Land Economics 58:1 (February): 33-51.

Robichek, Alexander A., Richard A. Cohn and John A. Pringle, 1972. Returns on Alternative Investment Media and Implications for Portfolio Construction. Journal of Business 45:3 (July): 427-443.

St. Louis, Larry V., 1980. A Measure of Regional Diversification and Efficiency. The Annals of Regional Science 14:1 (March): 2130.

Sharpe, William F., 1966. Mutual Fund Performance. Journal of Business 39:1, Part II (January): 119-138.

Siegel, Richard A., 1966. Do Regional Business Cycles Exist? Western Economic Journal 5:1 (December): 44-57.

Smith, Keith V. and John C. Schreiner, 1969. A Portfolio Analysis of Conglomerate Diversification. Journal of Finance 24:3 (June): 413-427.

Syron, Richard F., 1978. Regional Experience During Business Cycles: Are We Becoming More or Less Alike? New England Economic Review (November/December): 24-35.

U.S. Department of Commerce, Bureau of the Census, 1977 Census of Manufactures (Issued August, 1981) Washington, D.C.: GPO.

U.S. Department of Labor, Bureau of Labor Statistics, Employment and Earnings (monthly publication).

Weingartner, H. Martin, 1966. Capital Budgeting of Interrelated Projects: Survey and Synthesis. Management Science 12:7 (March): 485-516. 